\title{
Exploration of Fair Value Assessment of Stock Option with B-S Model
}

\author{
Ling Peng \\ Economics and Management School, Yibin University, Yibin, 644000, China
}

\author{
Keywords: Stock option, Fair value, B-S model, Assessment
}

\begin{abstract}
Stock option is an effective and feasible incentive method which is adopted by more and more listed companies in China. Accounting Standards for Business Enterprises No.11- Stock-based Payment issued by Ministry of Finance in February 2006 standardizes accounting treatment of stock option. The fair value of stock option is adopted for the form of measuring stock option. This paper discusses related problems of assessing fair value of stock option with B-S model and puts forward solutions through analyzing the influence factors of the fair value of stock option.
\end{abstract}

\section{Introduction}

Stock opinion is the incentive mechanism which is used most widely. In China, an increasing number of listed companies have prepared or are preparing implementation of incentive plan of stock option. There are four measuring methods for stock options: historical cost, minimum value, intrinsic value and fair value. About use of intrinsic value or fair value, there are many disputes in academic circle. Intrinsic value refers to the balance between market price of the company stock and the exercise price on the grant date. Larger balance means higher intrinsic value of stock option, i.e. "intrinsic value $=$ (predicted market price of tock - exercise price) $\mathrm{x}$ stocks subscribed". Companies should regard the balance between market price of stock and exercise price on the grant date as the cost of stock option and amortize it as expenses. But in practice, such practice is complex. It is necessary to make adjustments at the end of each accounting period. Thus, such method is not widely accepted. Fair value measuring method is introduced in China's norm. Fair value of stock option is the price each transaction party (companies and employees) can accept during granting stock option. It not just includes intrinsic value of tock option, but also includes time value. It covers all of stock option value. So, from this perspective, intrinsic value does not completely reflect real value of stock option. Time value is also an important constituent part of stock option value. So, in such case, it is more ideal to use fair value of stock option as the measuring method.

\section{Influencing factors of option value}

Option value is jointly composed of intrinsic value and time value. All factors influencing intrinsic value and time value are the factors influencing option value.

Intrinsic value refers to the option value when the option is executed at the agreed price. Generally, intrinsic value is greater than zero. Intrinsic value of call option is equal to the market value of basic financial assets minus the agreed price of the option. Intrinsic value of put option is equal to the agreed price of the option minus the market value of basic financial assets.

For sellers, time value reflects time risk within option transaction period; for buyers, it reflects the appreciation possibility of intrinsic value of the option. As the sellers will take time risk, they will require options tariff higher than intrinsic value when selling options. In fact, as time changes, fluctuations in prices of the subject matter may make options appreciate. So, buyers are willing to pay options tariff higher than intrinsic value. Thus, option value is always greater than intrinsic value. The difference between the two is called "time value". Usually, longer valid period of options means greater time value. As the option is close the maturity date, the time value reduces gradually. When the option expires, the time value will become zero.

The influencing factors of option value mainly influence the option value through influencing intrinsic value and time value. Main influencing factors are as follows: 


\section{Market value of underlying asset and negotiated price of options}

Since the income of call options during execution is equal to the difference between the market price and negotiated price of the underlying asset. So, if the price of the underlying asset is higher and the negotiated price is lower, the value of call options will be higher. For put options, since the income during execution is equal to the difference between negotiated price and the market value of the underlying asset, the value of put options is higher if the value of the underlying asset is lower and the negotiated price is higher.

\section{Valid period of options}

As time extends, the growth rate of time value of options is descending. For the options with the fixed maturity date, when other conditions are unchanged, the decrease in the time value is incremental as time passes. This means the decrease rate of time value of the options with long deadline will be lower than that of the options with short deadline when time lapses equally.

\section{Fluctuation rate of underlying asset price}

Fluctuation rate of underlying asset price is an index used to measure uncertainty of future price change of the underlying asset. Since the largest amount of loss of long options is only limited to option price and the largest profit amount depends on the difference between asset market value and negotiated price of the underlying asset when the option is executed, larger fluctuation rate is more beneficial to long options and option price should be higher.

\section{Risk-free interest rate}

Risk-free interest rate is one of influencing factors of option value. Risk-free interest rate level will influence time value and intrinsic value of options. When the interest rate increases, time value curve of options shifts towards the right; on the contrary, when the interest rate drops, time value curve of options shifts towards the left. The overall influence of interest rate level on interest rate level of the options is very limited. The key is the influence on intrinsic value of options. Call options impose positive influence, while put options impose reverse influence.

When other factors remain unchanged, if risk-free interest rate rises, expected growth rate of underlying asset price may increase, while present value of cash flow which may be received by buyers in the future will fall. The two factors make the value if put options drop. Thus, higher risk-free interest rate means lower value of put options. For call options, the rise in the growth rate of the underlying asset price will lead to the rise in the value of call options, while the decrease in present value of cash flow which may be received in the future will lead to the reduction of the value of cal options. The theories prove the effect of the former factor on the value of call options is larger than that of the latter factor. So, higher risk-free interest rate means higher value of call options.

In fact, risk-free interest rate is opportunity cost of option investment. Generally speaking, when risk-free interest rate drops, the opportunity cost of option investment will fall and option value will rise; on the contrary, when risk-free interest rate rises, the opportunity cost of option investment will increase and option value will drop. The effects of risk-free interest rate on option value are very complex. In specific applications, comprehensive analysis is needed. It is also required to judge the importance of effects according to special conditions so as to gain corresponding conclusions.

\section{Income of underlying assets}

Since participation in profit and interest payment of underlying assets will reduce underlying asset price and the negotiated price is not adjusted correspondingly, the income of underlying assets will make call option value drop and make put option value rise within the valid period of the options.

According to the above analysis, there are many factors deciding and influencing option price and the effects of each factor on option price are very complex. Influence directions and degrees are different. Each influencing factor is mutually supplemented and offset.

\section{Considerations in the model confirmed by fair value of stock option}

Since stock options awarded to employees are limited by some terms and conditions different from transaction options, it is hard to gain the market price in many conditions. If the transaction options with similar terms and conditions do not exist, it is required to estimate the fair value of the granted 
options with option pricing models. When selecting applicable option pricing models, enterprises should consider the factors considered by voluntary market participants who are familiar with conditions. All pricing models applicable to estimating options granted to employees should at least consider the following factors: exercise price of the option; option deadline; current price of underlying stock; predicted fluctuation rate of stock price; predicted dividend of stock price; risk-free interest rate of stock option within the deadline. Besides, when enterprise select option pricing models, they also should consider other factors considered by voluntary market participants who are familiar with conditions, excluding the vesting conditions and re-awarding characteristic factors which are not considered during confirming the fair value. During confirming fair value of stock options ranted to employees, it is also necessary to consider the possibility of early exercise. Sometimes, since options cannot be transferred freely, or employees must exercise all vesting options before terminating the labor contract, the effects of early exercise must be considered in such cases. In practice, the fair value of stock options can be estimated with B-S valuation model. In this model, enterprises should consider fair value of the stock on the grant date, risk-free interest rate, predicted dividend, predicted fluctuation rate of stock price, current price of underlying stocks and valid period of options etc.

\section{Assessment fair value of stock option with B-S model}

Any model is assumed on the basis of certain market. B-S model has following fundamental assumptions:

(1) Risk-free interest rate is a known constant and does not change with time.

(2) The underlying security is the stock; the changes in underlying stock price comply with random walk, but such random walk can make the return rate of stocks present logarithmic normal distribution.

(3) The underlying stocks do not receive dividends.

(4) The option is European style option, i.e. the right can only be exercised on the maturity date.

(5) In the whole transaction process, there is no transaction cost or stamp duty.

(6) There is no any limitation (such as cash deposit) for short selling. Investors can freely use the funds gained from short selling.

In China, when the underlying securities participate in profit distribution and ex-dividend, the ex-dividend adjustment should be made for the exercise price. So, the assumption of no dividends is unnecessary.

In B-S option pricing model, option price depends on the following dive parameters: market price of the underlying asset, exercise price, maturity deadline, risk-free interest rate and price fluctuation of the underlying asset (i.e. standard deviation of the return on the underlying asset). Among these parameters, the first three parameters are certain numerical values which can be gained easily. But, estimated values of risk-free interest rate and price fluctuation of the underlying asset should be gained through certain calculations. Usually, there exists a rational interval for the expectation of future fluctuation rate and exercise behavior. At this moment, every possible amount within the interval multiplies by the probability of occurrence. The expected value of the above input variables can be worked out through weighting.

\section{Estimation of price fluctuation rate of underlying assets}

There are two methods to estimate price fluctuation rate of underlying assets: historical fluctuation rate and implied fluctuation rate. Historical fluctuation rate is the standard deviation of price yield rate calculated from historical data of underlying asset price. Implied fluctuation rate is calculated through substituting the parameters except fluctuation rate and option offer into B-S option pricing formula. Since B-S option pricing formula is complex, the computer is generally needed to calculate implied fluctuation rate. Obviously, the fluctuation rate gained can be regarded as market expectation for future fluctuation rate. The fluctuation rate issued in option pricing model is annual standard deviation of continuous compounding return rate within a period. The fluctuation rate is usually expressed with the year, regardless of the time span. Among the parameters used by B-S formula, 
three parameters are related to time: deadline, risk-free interest rate and fluctuation rate. It is worth noting that unit of time of the three parameters must be the same.

\section{Estimation of risk-free interest rate}

Risk-free interest rate generally refers to internal rate of return zero-coupon bond can gain currently with residual maturity of option exercise price equal to predicted deadline the valued option. Without such national debt, or when environment indicates internal rate of return of zero-coupon bond cannot represent risk-free interest rate, appropriate alternate interest rate should be used. During estimation of the fair value of other options with the valid period equal to predicted deadline of the valued option, if market participants adopt proper alternate interest rate rather than internal rate of return of zero-coupon bond to confirm risk-free interest rate, enterprises should use this proper alternate interest rate.

\section{Prediction of early exercise}

Out of various reasons, employees often exercise stock options before the expiry date. The following factors should be considered during prediction of early exercise: waiting period; mean existence time of previous similar options; price of underlying stocks; level of the employees in the enterprise; predicted fluctuation rate of underlying stocks. When estimating the predicted deadline of options of an employee group, enterprises can adopt weighted average method to estimate overall predicted option deadline of this group of employees. If proper groups can be classified according detailed data of employees' exercise behaviors, enterprises can base the estimation on weighted average of predicted deadline, i.e. make the employees with similar exercise behaviors into one group and estimate the options according to different levels.

Generally speaking, B-S option pricing formula has certain deviations, but it is still one of the best models to explain dynamics of option price. It thus can be seen that we need to consider multiple factors hen using B-S model to estimate fair value of stock options so as to estimate rationally and correctly as far as possible.

\section{References}

[1] Ministry of Finance of the People's Republic of China: Accounting Standards for Business Enterprises 2006, Beijing: Economic Science Press, 2006

[2] Ministry of Finance of the People's Republic of China: Accounting Standards for Business Enterprises - Application Guide 2006, Beijing: China Financial and Economic Publishing House, 2006

[3] Accounting Qualification Evaluation Center under Ministry of Finance. Intermediate Accounting Practice, Beijing: Economic Science Press, 2013

[4] Chen Meihua: Study on confirming fair value of stock option, Journal of Guangdong Business College, 2008.6

[5] Zheng Zhenlong: Derivative products, Wuhan: Wuhan University Press, 2005

[6] Zhap Li'e: On accounting problems of stock option in listed companies, China High Technology Enterprises, 2009 (20) 